\title{
Technical Note: Non-Sink Dissolution Media for Identification of Functional Formulation Excipients-The Case of a Precipitation Inhibitor
}

e-mail:maria_cruanes@merck.com maria.t.cruanes@gmail.com

\author{
Maria T. Cruañes*, Kimberly Bentz, Wei Xu, and Laura Artino \\ Pharmaceutical Sciences and Clinical Supply, Merck Research Laboratories, Merck and Co., \\ West Point, PA 19486, USA
}

KEYWORDS: Media selection, excipient selection, transient solubility, non-sink conditions, antinucleating agent, antiprecipitating agent, precipitation inhibitor, low solubility compound, supersaturation.

\section{INTRODUCTION}

D ue to the abundance of dissolution methodology and media available to pharmaceutical development and quality scientists, it is advisable that method selection criteria be dictated by the purpose of the measurement. This is particularly important when dissolution is used as a tool to guide formulation design. These cases often require the use of conditions that are relevant to the in vivo situation, but most critically, they are chosen to tease out an excipient's ability to perform its intended function. This note aims to illustrate how purposeful media selection can help probe the functionality of an excipient to be used in a solid oral dosage form of a low solubility compound. In this example, the active pharmaceutical ingredient (API) is a crystalline potassium salt of a weak acid with a $\mathrm{p} K_{\mathrm{a}}=6.8$, and the excipient in question is hydroxypropyl methylcellulose (HPMC). The API has relatively high solubility, $71 \mathrm{mg} /$ $\mathrm{mL}$ in water or at a $\mathrm{pH}>\mathrm{p} K_{\mathrm{a}}$, which drops to $0.01 \mathrm{mg} /$ $\mathrm{mL}$ (the equilibrium solubility of the protonated free form measured more than $24 \mathrm{~h}$ after the crystalline salt was introduced in aqueous medium) at $\mathrm{pH}<6.8$, the $\mathrm{pH}$ expected in the gastrointestinal (GI) tract (1). The HPMC excipient was chosen for its potential ability to act as an antinucleating agent (2), inhibit precipitation of the drug at a $\mathrm{pH}<\mathrm{p} K_{\mathrm{a}}$, and induce super saturation, thus enhancing in vivo solubility and absorption. To assess the utility of the excipient for an oral dosage form, in vitro dissolution of the neat API is carried out under non-sink conditions, at a $\mathrm{pH}<\mathrm{p} K_{\mathrm{a}}$ and a dose-relevant concentration, in the presence and absence of HPMC. Next, dissolution of the formulated API is carried out under non-sink conditions, over a $\mathrm{pH}$ range that is $\mathrm{Gl}$ relevant, at dose-relevant concentrations. Subsequently, preclinical models are used to assess further the in vivo utility of the HPMC excipient before defining a formulation for human trials. A range of drug and excipient concentrations may be explored in vitro depending on predicted clinical doses and dosage form considerations, respectively. Two ex-

${ }^{*}$ Corresponding author. amples of in vitro measurements of neat and formulated API are presented below.

\section{RESULTS AND DISCUSSION \\ Dissolution of the Neat API}

First, the rate of dissolution or "transient solubility" of the neat API was measured in $\mathrm{pH} 4$ media containing the HPMC excipient at various levels. The concentrations of the API and HPMC were chosen to screen realistic APIexcipient ratios suitable for the prospective immediaterelease solid formulation (5:1, 10:1, 20:1, and no HPMC). The drug concentration was fixed at $0.4 \mathrm{mg} / \mathrm{mL}$ (equivalent to a 200-mg dose in a biorelevant volume of $500 \mathrm{~mL}$ ), which is 40 times greater than the equilibrium solubility. To achieve the desired API-excipient ratio, 40, 20, 10, and $0 \mathrm{mg}$ of HPMC was dissolved in $50 \mathrm{mM}$ citrate buffer $(\mathrm{pH} 4)$ prior to addition of the $200 \mathrm{mg}$ of API directly in the vessel. It is recommended that a range of dose-relevant concentrations be tested. Only one is shown in Figure 1. The purpose was to test the effectiveness of the antinucleating excipient in a non-sink environment in which the drug by itself would have precipitated. Thus, no surfactant was utilized. Figure 1 illustrates the transient solubility of the API at pH 4. In the absence of HPMC, the compound only partially dissolved and began to precipitate within 20 min maintaining some residual supersaturation of approximately $0.04 \mathrm{mg} / \mathrm{mL}$. In the presence of HMPC, the drug remained solubilized at $0.4 \mathrm{mg} / \mathrm{mL}$, which is 10 times greater than the residual solubility in the absence of HPMC or 40 times the equilibrium solubility, staying in the fully supersaturated state for at least $3 \mathrm{~h}$. These results confirm the capability of HPMC to prevent the in vitro precipitation of the drug, presumably by inhibiting the nucleation or growth rate (2) necessary for crystallization of the protonated species at a $\mathrm{pH}$ below the $\mathrm{p} K_{\mathrm{a}}$. No significant differences were observed over the range of HPMC levels studied, indicating that these levels are above a threshold needed for complete precipitation inhibition. The HPMC level may then be chosen within this range based on other dosage form considerations such as stability and mechanical properties. 


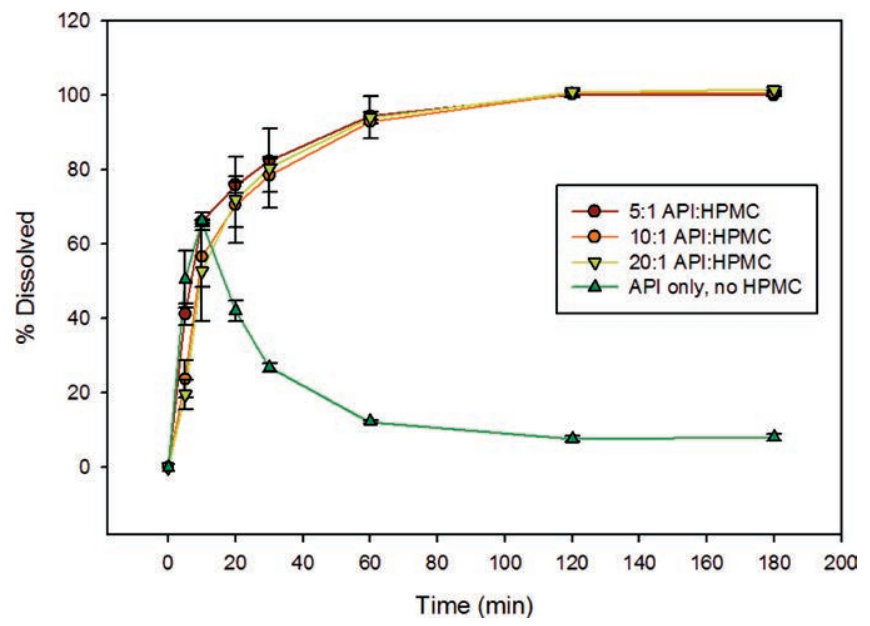

Figure 1. Dissolution profiles of $200 \mathrm{mg}$ of neat API in $500 \mathrm{~mL}$ of $50 \mathrm{mM}$ citrate buffer ( $\mathrm{pH}$ 4) containing no HPMC or HPMC predissolved at various levels to provide API-HPMC ratios of 5:1, 10:1, and 20:1. (USP Apparatus 2 at $100 \mathrm{rpm}$ through $60 \mathrm{~min}, 150 \mathrm{rpm}$ beyond $60 \mathrm{~min}, 37^{\circ} \mathrm{C}, n=3$; error bars represent observed range.

\section{Dissolution of the Formulated API}

In the next experiment, the dissolution of API formulated into HPMC-containing solid granules was measured at non-sink conditions and Gl-relevant pH levels. A midpoint API-HPMC ratio of 10:1 and dose-relevant concentration of $100 \mathrm{mg}$ in $500 \mathrm{~mL}(0.2 \mathrm{mg} / \mathrm{mL})$ is depicted in Figure 2. The granules contained other common excipients not known to be antinucleating agents, such as dicalcium phosphate, microcrystalline cellulose, and sodium croscarmellose. The dissolution media were $0.01 \mathrm{~N} \mathrm{HCl}(\mathrm{pH} 2), 50 \mathrm{mM}$ citrate buffer $(\mathrm{pH} 4)$, and $50 \mathrm{mM}$ phosphate buffer (pH 6.8) without HPMC or surfactant. In Figure 2, the granules traces are compared with that of $100 \mathrm{mg}$ of neat API in $\mathrm{pH} 4$ medium without HPMC. The neat API began to precipitate within $20 \mathrm{~min}$, achieving a residual supersaturation solubility of approximately $0.04 \mathrm{mg} / \mathrm{mL}$. The HPMC-containing granules released approximately $100 \%$ of the API achieving about $0.2 \mathrm{mg} /$ $\mathrm{mL}$ solubility, which is about 20 times the equilibrium solubility or about five times the observed residual supersaturation solubility. The dissolution profiles indicate that the HPMC incorporated in the solid formulation granules functioned as a precipitation inhibitor by maintaining the compound completely solubilized in its supersaturated state for at least three hours. The granules dissolved somewhat faster at lower $\mathrm{pH}$, reaching near complete release in $20 \mathrm{~min}$ at $\mathrm{pH} 2$ versus $120 \mathrm{~min}$ at $\mathrm{pH} 6.8$ (Figure 2). This is unrelated to the HPMC and can be explained by the faster rate of granule disintegration in acidic media caused by the dicalcium phosphate, which is more soluble at low $\mathrm{pH}$ (3).

Subsequent pharmacokinetic (PK) experiments in dogs confirmed the utility of HPMC, predicted by the in vitro studies, when the solid formulation containing 10:1 API-

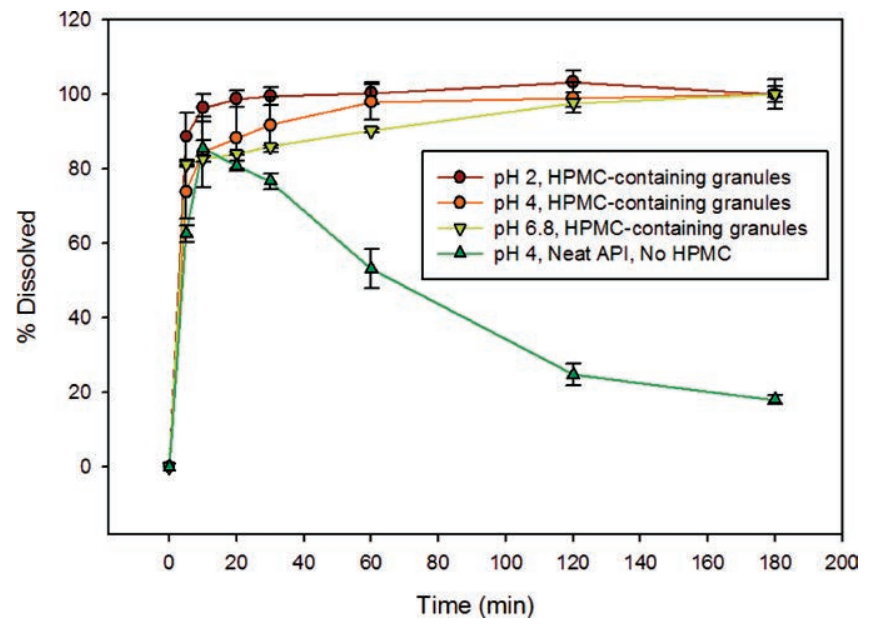

Figure 2. Dissolution of $100 \mathrm{mg}$ neat API and API from HPMC-containing formulation granules with API-HPMC ratio of 10:1 in $500 \mathrm{~mL}$. Media buffers are $0.01 \mathrm{~N} \mathrm{HCl}(\mathrm{pH} 2), 50 \mathrm{mM}$ citrate buffer ( $\mathrm{pH} 4$ ), and $50 \mathrm{mM}$ phosphate buffer ( $p H$ 6.8) without HPMC. (USP Apparatus 2, 100 rpm through $60 \mathrm{~min}, 150 \mathrm{rpm}$ beyond $60 \mathrm{~min}, 37^{\circ} \mathrm{C}, n=2$, error bars represent observed range. As is sometimes the case with granule dissolution, due to minor powder segregation, the profiles did not reach $100 \%$ dissolution, but slightly more or less at $180 \mathrm{~min}$. Thus, the traces are normalized to their final 180-min value to facilitate comparison.)

HPMC produced an exposure enhancement $70 \%$ greater than that of a solid formulation without HPMC (data not shown).

\section{CONCLUSION}

Dissolution of the neat salt of a weak acid under non-sink conditions at a $\mathrm{pH}<\mathrm{p} K_{\mathrm{a}}$ and a dose-relevant concentration in the presence and absence of HPMC enabled the rapid assessment of this excipient's antiprecipitating effect on the drug. Dissolution of solid APIHPMC-containing granules under non-sink conditions at various $\mathrm{pH}$ levels (Gl-relevant, below $\mathrm{p} K_{\mathrm{a}}$ ) further demonstrates the potential of the excipient to enhance in vivo solubility and absorption. Subsequent preclinical PK experiments confirm the utility of the HPMC excipient. If the in vitro dissolution tests had used conventional media at $\mathrm{pH}$ levels above the $\mathrm{p} K_{\mathrm{a}}$ or contained solubilizing surfactants to achieve sink conditions, the drug would have dissolved in all cases, and the effect of the antinucleating agent would not have been discernible. This in vitro methodology may be used to quickly screen a menu of nucleation-inhibiting excipients, their grades, and sources on salts of weak acids and other kind of supersaturating drugs (e.g., amorphous drugs and salts of conjugate acids of weak bases ${ }^{1}$-the latter are typically soluble at gastric $\mathrm{pH}$ but insoluble at intestinal $\mathrm{pH}$ ) that can benefit from their antinucleating effect. Further efficiencies can be gained from miniaturizing the in vitro

'Unlike the case of the salt of a weak acid, the dissolution medium $\mathrm{pH}$ for the salt of a protonated weak base has to be above the $p K_{a}$ of the conjugate acid. 
equipment. Additionally, dissolution of the formulation under non-sink conditions, at a $\mathrm{pH}<\mathrm{p} K_{\mathrm{a}}$ (for the salt of a weak acid), in media without the excipient can be used to further test excipient functionality. The example shows how purposefully selected media for non-sink in vitro work can support the identification of a critical formulation component consistent with the Quality-byDesign approach (4).

\section{REFERENCES:}

1. Kararli, T. Comparison of the gastrointestinal anatomy, physiology, and biochemistry of humans and commonly used laboratory animals. Biopharm. Drug. Dispos. 1995, 16 (5), 351-380.
2. Raghavan, S. L.; Trividic, A.; Davis, A. F.; Hadgraft, J. Crystallization of hydrocortisone acetate: influence of polymers. Int. J. Pharm. 2001, 212 (2), 213-221.

3. Kibbe, A. H., Ed. Handbook of Pharmaceutical Excipients, 3rd ed.; American Pharmaceutical Association: Washington, DC, 2000; pp 60-63.

4. International Conference on Harmonisation of Technical Requirements for Registration of Pharmaceuticals for Human Use. Pharmaceutical Development, Q8(R2); ICH Harmonized Tripartite Guideline: Geneva, Switzerland, 2009. http://www. ich.org/fileadmin/Public_Web_Site/ICH_Products/ Guidelines/Quality/Q8_R1/Step4/Q8_R2_Guideline.pdf (accessed Oct 18, 2013). 